\title{
Related Party Transaction Berpengaruh Terhadap Biaya Audit Related Party Transaction Influences Audit Costs
}

\author{
Senato Erasandi* \\ Program studi Akuntansi, Fakultas Ekonomi dan Bisnis, Universitas Airlangga, Indonesia
}

The purpose of this study is to analyze the effect of related party transactions on audit fees. This study uses 67 samples listed on the Indonesia Stock Exchange for the period 2017 to 2018. The analysis used in this study is the Multiple Regression analysis model that is processed with SPSS 20 software. This study found that related party transactions were positively and significantly related to audit fees. The results show that related party transactions can cause the company to have a high risk so that it can increase the audit fees paid by the company.

Keywords: Related party transaction, Biaya Audit

Tujuan dari penelitian ini adalah untuk menganalisis pengaruh transaksi pihak berelasi terhadap biaya audit. Penelitian ini menggunakan 67 sampel yang terdaftar di Bursa Efek Indonesia untuk periode 2017 hingga 2018. Analisis yang digunakan dalam penelitian ini adalah model analisis Regresi Berganda yang diproses dengan perangkat lunak SPSS 20. Studi ini menemukan bahwa transaksi pihak terkait positif dan signifikan terkait dengan biaya audit. Hasil menunjukkan bahwa transaksi pihak terkait dapat menyebabkan perusahaan memiliki resiko yang tinggi sehingga dapat meningkatkan biaya audit yang

OPEN ACCESS ISSN 2548-3501 (online)

Edited by:

Eny Maryanti

Reviewed by:

Riski $A$.

*Correspondence:

Senato Erasandi

Senatoerasandi11@gmail.com

Received: 24 Desember 2019

Accepted: 20 Januari 2020

Published: 31 Januari 2020

Citation:

SE (2020) Related Party Transaction Berpengaruh Terhadap Biaya Audit. Journal of accounting Science. 4:1. doi: 10.21070/jas.v4i1.393 dibayarkan oleh perusahaan.

Keywords: Related Party Transaction, Audit costs 


\section{PENDAHULUAN}

Transaksi pihak berelasi merupakan transaksi antara perusahaan dan individu atau organisasi yang terkait dengan perusahaan, seperti manajer, dewan direksi, pemegang saham utama, dan perusahaan afiliasi. Transaksi dengan pihak terkait meliputi aktivitas seperti penjualan dan pembelian aset, penjaminan pinjaman, dan pertukaran aset dengan kualitas yang berbeda.transaksi pihak berelasi memiliki dua pendangan yang berbeda ditinjau darisisi positif dan sisi negatif, di sisi positif transaksi pihak berelasi dapat meningkatkan nilai karena dapat dimanfaatkan oleh kelompok bisnis untuk berbagi sumber daya, mengurangi biaya transaksi, dan sebagai hasilnya dapat meningkatkan pengembalian aset. Sisi negatif pada transaksi pihak berelasi yakni dapat digunakan secara oportunistik oleh pemegang saham pengendali yang menangani sendiri untuk mengambil keputusan untuk keuntungan pribadi tanpa melalui persetujuan pemegang saham minoritas.

Pengaturan skema bisnis antar pihak berelasi yakni adanya transfer pricing. Contoh dari transfer pricing adalah dengan transaksi penjualan pada pihak berelasi yang tidak sebanding atau lebih rendah dari penjualan pada transaksi yang tidak memiliki hubungan istimewa (Atanasov et al. (2014) Pemegang saham mayoritas yang memiliki kekuasaan untuk mengendalikan perusahaan dapat mengatur setiap transaksi melalui pihak-pihak terkait untuk mengambil keuntungan pribadi atau mengalihkan sumber daya perusahaan dari pemegang saham minoritas ke diri mereka sendiri. Pemegang saham mayoritas juga dapat menggunakan hubungan mereka yang memliki pengaruh terhadap kelompok bisnis untuk menyusun transaksi dalam kelompok dengan cara yang memungkinkan laba dialihkan dari perusahaan dalam suatu kelompok baik ke kantong pemegang saham pengendali secara langsung atau untuk meningkatkan posisi keuangan perusahaan yang bermasalah dalam kelompok yang sama.Transaksi pihak berelasi dapat menyesatkan pengguna laporan keuangan.

Laporan keuangan digunakan oleh pengguna laporan keuangan yaitu kreditur, debitur dan shareholder untuk pengambilan keputusan ekonomi. Laporan keuangan sebelum digunakan untuk pengambilan keputusan ekonomi harus melalui proses audit yang dilakukan oleh auditor eksternal. Auditor eksternal dalam melakukan proses audit harus melihat resiko yang dimiliki oleh perusahaan. Transaksi pihak berelasi menjadi salah satu pertimbangan khusus bagi para auditor untuk menyelesaikan proses audit (Tuanakotta (2015)

Keberadaan pihak berelasi di indonesia diatur dalam PSAK 7 (penyesuaian 2014) tentang pengungkapan pihak-pihak berelasi dimana PSAK tersebut bertujuan untuk mengatur pengungkapan transaksi pihak berelasi yang terjadi pada suatu perusahaan secara transparan dalam laporan keuangannya. Dengan adanya PSAK 7 (penyesuaian 2014) dapat membuat pengguna informasi mengetahui secara lebih jelas mengenai pihak berelasi yang dilakukan oleh perusahaan. Pihak berelasi merupakan pihak yang memiliki hubungan spesial dengan pihak lain.

Teori menyatakan terdapat dua pandangan tentang transaksi pihak berelasi, teori pertama teori pihak berelasi merupakan kebutuhan nasional untuk memenuhi tujuan ekonomi perusahaan (efficiency-enhancing theory). Teori kedua menunjukan bahwa transaksi pihak berelasi dapat menimbulkan isu keagenan, masalah agensi muncul ketika maanjer dengan tindakan oportunitistiknya memaksimalkan pendapatan mereka sendiri dan merugikan pemegang saham (Jensen and Meckling (1976) . Manajer dapat mementingkan diri sendiri melalui transaksi pihak berelasi dengan mengambilalih sumber daya perusahaan dan mengalikan kekayaan dari perusahaan ke keuntungan pribadi (Gordon and Henry (2005)

Transaksi pihak berelasi dapat digunakan sebagai "red flag" dapat meningkatkan risiko salah saji material (Kohibeck and Brian W (2014) . Kehadiran transaksi pihak berelasi dapat meningkatkan biaya audit yang dikeluarkan oleh perusahaan. Akuntan publik untuk melakukan proses audit memeriksa resiko yang dimiliki oleh perusahaan. Transaksi pihak berelasi meningkatkan resiko salah saji material sehingga dapat meningkatkan upaya auditor dan dapat meingkatkan biaya audit yang dikeluarkan. Penelitian Habib et al. (2015) ; AlDhamari et al. (2017) menyatakan bahwa transaksi pihak berelasi dapat meningkatkan biaya audit perusahaan.

Penelitian ini menguji pengaruh dari transaksi pihak berelasi terhadap biaya audit yang dikeluarkan oleh perusahaan. Variabel kontrol yang digunakan dalam penelitian ini yaitu return on asset, ukuran perusahaan, dan kantor akuntan publik. Tahun penelitian dilakukan pada tahun 2017 sampai 2018 pada indutri manufaktur yang terdaftar pada bursa efek Indonesia.

\section{Kerangka Berfikir}

Penelitian ini berfokus pada transaksi pihak berelasi terhadap biaya audit. Perusahaan yang melakukan transaksi dengan pihak berelasi rentan dengan resiko salah saji material . Kohlbeck and Mayhew (2010) menyatakan bahwa transaksi pihak berelasi dapat digunakan sebagai red flag yang dapat meningkatkan resiko sehingga auditor dalam memeriksa laporan keuangan menggunakan upaya yang lebih agar dapat menghasilkan opini yang sesuai. Hal tersebut dapat meningkatkan biaya audit yang dikeluarkan oleh perusahaan.

Penelitian ini juga menggunakan variabel kontrol yakni return on asset, ukuran perusahaan, dan akuntan perusahaan. Variabel kontrol diperlukan untuk menguatkan model pada penelitian transaksi pihak berelasi terhadap biaya audit. Pada Gambar 1 merupakan kerangka berfikir penelitian ini:

[Figure 1 about here.] 


\section{Pengembangan Hipotesis}

Transaksi pihak berelasi banyak menjadi perhatian diantara pelaporan keuangan dan auditing, terutama setelah banyak skandal keuangan yang ada di seluruh dunia. Secara teori transaksi pihak berelasi memiliki dua sudut pandang. Sudut pandang yang pertama transaksi pihak berelasi terkait dengan efficiency-enhancing theory yang menyatakan bahwa transaksi dengan pihak berelasi digunakan oleh kelompok bisinis sebagai cara untuk mengalokasikan sumber daya dengan leih baik dan dapat mengurangi biaya transaksi (Al-Dhamari et al. (2017) . Selain itu, pihak terkait dengan pengetahuan mendalam dan pengalaman kegiatan perusahaan dapat memberikan layanan kepada perusahaan lebih efektif (Gordon and Henry (2005).

Sudut pandnag kedua menyatakan transaksi pihak berelasi dapat menimbulkan isu keagenan, dimana transaksi pihak berelasidapat menyebabkan kerugian atas kegagalan yang dialami perusahaan karena tindakan oportunistik(Kohlbeck and Mayhew (2010). Hubungan pihak berelasi yang signifikan dapat memiliki pengaruh terhadap posisi keuangan dan laba rugi perusahaan. Argumen terkait transaksi pihak berelasi terhadap laporan keuangan, auditor memiliki tanggung jawab untuk mengidentifikasi transaksi pihak berelasi sebagai salah satu resiko salah saji material. Kohlbeck and Mayhew (2010) menyatakan bahwa transaksi pihak berelasi dapat digunakan sebagai red flag yang dapat meningkatkan resiko sehingga auditor dalam memeriksa laporan keuangan menggunakan upaya yang lebih agar dapat menghasilkan opini yang sesuai.

Simunic (1980) merumuskan bahwa biaya audit dipengaruhi oleh besar kecilnya auditee, komplesitas audit dan resiko yang dimiliki perusahaan. Sehubungan dengan resiko audit, transaksi pihak berelasi merupakan salah satu pertimbangan khusus oleh auditor eksternal dalam melakukan proses audit. Sehingga auditor memerlukan waktu dan upaya untuk melakukan proses audit dan berdampak bada biaya audit (Habib et al. (2015)Al-Dhamari et al. (2017)

$\mathrm{H1}$ : transaksi pihak berelasi berpengaruh positif terhadap besaran biaya audit perusahaan.

\section{METODE}

Populasi penelitian ini merupakan seluruh perusahaan manufaktur yang terdaftar di Bursa Efek Indonesia (BEI) tahun 2017-2018. Penelitian ini menggunakan jenis data sekunder yang diambil dari informasi yang tersaji pada Annual Report. Sebanyak 67 perusahaan terpilih menjadi sampel penelitian berdasarkan teknik purposive sampling dengan kriteria padaTabel 1

[Table 1 about here.]

\section{Pengukuran Variabel.}

RPT_Sales dapat dirumuskan sebagai berikut

$$
\text { RPT Sales }=\frac{\text { Related party sales }}{\text { Unrelated party sales }}
$$

Adapun teknik analisis yang digunakan meliputi analisis statistika deskriptif, uji asumsi klasik, dan uji hipotesis (Ghozali (2011). Analisis statistika deskriptif berisi informasi mengenai karakteristik data penelitian berupa nilai minimum, nilai maksimum, nilai rata-rata dan standar deviasi. Pengujian hipotesis dilakukan menggunakan analisis regresi linear berganda. Berikut model persamaan regresi moderasi dalam penelitian ini:

AudFeeit $=\alpha 0+\beta 1 R P T \_S A L E S i t+$ $\beta 3$ BIG4it $+\beta 4 R O A i t+\beta 5$ SIZEit + eit

Keterangan:

AudFee $=$ Audit Fee yang dikeluarkan oleh entitas gopublik

$\alpha_{0}=$ Konstanta

RPT_SALES $=$ Transaksi pihak berelasi perusahaan i tahun $\mathrm{t}$

BIG4 = Auditor big 4 Menggunakan dummy, 1 di audit oleh Big4

dan 0 untuk di audit selain Big4

ROA $=$ Return of asset

SIZE $=$ Ukuran perusahaan

$\varepsilon$ it $=$ Koefisien error

\section{HASIL PEMBAHASAN}

Hasil Statistik Deskriptif

Berdasarkan tabel statistik deskriptif Tabel 2 , dapat diketahui bahwa variabel dependen dalam penelitian ini yaitu biaya audit memiliki nilai rata-rata sebesar 20.8392 dalam rupiah berarti $\mathrm{Rp} 825$ juta, ini berarti bahwa rata-rata perusahaan di Indonesia pada 2017 sampai 2018 membayar jumlah biaya audit sebesar Rp 825 juta kepada auditor. Rentang ini cukup tinggi pada variabel ini, dilihat dari perbedaan antara nilai maksimum dan minimum, menggambarkan bahwa sampel perusahaan dalam penelitian ini mewakili jumlah nominal biaya audit dari kecil ke besar.

Variabel independen dalam penelitian ini adalah transaksi pihak berelasi yang diukur dengan penjulan dibagi dengan penjualan pada pihak berelasi digunakan dalam penelitian (Wong et al. (2015) ; Cheng and Leung (2014); Chen et al. (2014) . Nilai rata-rata yang diperoleh adalah 0.1977. Hasil menunjukan bahwa rata-rata sampel dalam perusahaan memiliki 19\% transaksi dengan perusahaan yang memiliki hubungan relasi dengan perusahaan tersebut.

Variabel kontrol yang digunakan dalam penelitian yakni return on asset, ukuran perusahaan dan akuntan publik. Pada variabel ROA didapatkan nilai minimum sebesar $-0,29$ dan nilai maksimal sebesar 0,21 , pada variabel ukuran perusahaan didapatkan nilai minimal logaritma aset sebesar 26,44 dan nilai maksimal sebesar 31,68. Variabel kantor akuntan publik pada perusahaan manufaktur yang mengaudit pada KAP BIG 4 sebesar $56,7 \%$ dan yang di auidt oleh KAP biasa yakni sebesar $43,3 \%$. 
[Table 2 about here.]

\section{Hasil Analisis Regresi}

Hipotesis dalam penelitian ini di Uji dengan anlisis regresi moderasi. Sebelum di lakukan uji regresi moderasi peneliti melakukan uji asumsi klasik yakni uji normalitas data, uji heterokedastisitas, dan uji multikolinearitas. Uji asumsi klasik dilakukan untuk mengetahui data penelitian yang sudah terdistribusi normal dan data bebas dari heterokedastisitas dan multikolinearitas. Model penelitian ini sudah layak dilakukan uji regresi linear berganda karena sudah lolos dari uji asumsi klasik.

nilai adjusted $R 2$ sebesar 0,723 yang artinya variabel independen mampu menjelaskan variabel dependen sebesar 72,3\% sementara $27,7 \%$ sisanya dipengaruhi oleh factor lain diluar model penelitian. Hasil dari pengaruh transaksi pihak berelasi terhadap biaya audit menunjukan nilai signifikansi 0,006 yang menunjukan bahwa transaksi pihak berelasi berpengaruh positif terhadap biaya audit.

\section{[Table 3 about here.]}

\section{Pengaruh Transaksi Pihak Berelasi terhadap Biaya Audit}

Hasil penelitian pada Tabel 3 yang dilakukan pada model penelitian ini menunjukan bahwa hasilnya konsisten dengan hipotesis pertama yang menyatakan bahwa transaksi pihak berelasi berpengaruh positif signifikan terhadap biaya audit. Tingkat signifikansi sebesar 5\% $(0.006<0.05)$, sehingga $\mathrm{H}_{1}$ diterima. Penjelasan hasil dalam penelitian ini adalah adanya hubungan antara perusahaan yang melakukan transaksidiyakini dapat meningkatkan resiko bawaan (inheren risk) dari perusahaan(Al-Gamrh et al., 2017).

Transaksipihak berelasi dapat menimbulkan isu keagenan, dimana transaksi pihak berelasidapat menyebabkan kerugian atas kegagalan yang dialami perusahaan karena tindakan oportunistik (Kohlbeck and Mayhew (2010) Kohlbeck \& Mayhew, 2010 Jian and Wong (2004) . Hubungan pihak berelasi yang signifikan dapat memiliki pengaruh terhadap posisi keuangan dan laba rugi perusahaan. Argumen terkait transaksi pihak berelasi terhadap laporan keuangan, auditor memiliki tanggung jawab untuk mengidentifikasi transaksi pihak berelasi sebagai salah satu resiko salah saji material. Kohlbeck and Mayhew (2010) menyatakan bahwa transaksi pihak berelasi dapat digunakan sebagai red flag yang dapat meningkatkan resiko sehingga auditor dalam memeriksa laporan

\section{REFERENCES}

Al-Dhamari, R. A., Al-Gamrh, B., Ismail, K. N. I. K., and Ismail, S. S. H. (2017). Related Party Transactions and Audit Fees: The Role of The Internal Audit Function. Journal of Management \& Governance 22, 187-212. doi: 10.1007/s10997017-9376-6.

Atanasov, V. A., Black, B. S., and Ciccotello, C. S. (2014). Unbundling And Measur- keuangan memakukan upaya yang lebih agar dapat menghasilkan opini yang sesuai. Sehubungan dengan resiko audit, transaksi pihak berelasi merupakan salah satu pertimbangan khusus oleh auditor eksternal dalam melakukan proses audit. Sehingga auditor memerlukan waktu dan upaya untuk melakukan proses audit dan berdampak bada biaya audit lebih tinggi.

Hasil ini juga selaras dengan sudut pandang Agency theory yang menyakatakan bahwa transaksi pihak berelasi dapat menyebabkan kerugian perusahaan yang diakhibatkan oleh tindakan oportunistik. Hal tersebut mengakhibatkan resiko lebih tinggi dimiliki oleh perusahaan yang melakukan penjulan dengan pihak berelasi. Perusahaan yang memiliki resiko yang tinggi, sesuai dengan teori dan hasil empiris bahwa perusahaan yang melakukan transaksi pihak berelasi membayar biaya audit lebih tinggi dari perusahaan yang tidak terkoneksi.

\section{KESIMPULAN}

Penelitian ini bertujuan untuk menganalisis pengaruh transaksi pihak berelasi terhadap biaya audit. Berdasarkan pengujian hipotesis pertama ditemukan bahwa adanya koneksi politik dalam perusahaan berpengaruh signifikan terhadap biaya audit. Perusahaan yang memiliki transaksi pihak berelasi dianggap memiliki risiko lebih tinggi daripada perusahaan lain yang tidak melakukan transaksi dengan relasi dan akibatnya auditor akan meningkatkan upaya audit yang diperlukan dan implikasinya terhadap biaya audit yang tinggi yang dibebankan (Habib et al. (2015) ; Al-Dhamari et al. (2017)

Penelitian ini memiliki keterbatasan, yang pertama masih sedikitnya perusahaan yang mengungkapkan biaya audit dalam laporan tahunannya. Saran untuk penelitian selanjutnya untuk menambah variabel yang memiliki pengaruh terhadap biaya audit seperti koneksi politik dan ceo busy.

\section{PENDANAAN}

Sumber dana yang digunakan dalam penelitian ini adalah mandiri dari peneliti sendiri.

\section{UCAPAN TERIMA KASIH}

Peneliti mengucapkan terima kasih kepada semua pihak yang telah mendukung penelitian ini.

ing Tunneling.

Chen, Y., Chen, C. H., and Chen, W. (2014). The Impact of Related Party Transactions on The Operational Performance of Listed Companies in China. Journal of Economic Policy Reform 12, 285-297.

Cheng, M.-A. and Leung, N. W. (2014). Ownership Structure, Ongoing Related Party Trasactions And Corporate Performance: Evidenced From ChinaED FIRMS. Corporate Ownership and Control 11, 446-464. doi: 10.22495/ cocv11i2c5p2. 
Ghozali, I. (2011). Aplikasi Analisis Multivariate Dengan Program SPSS, and others (ed.) (Semarang: BP Universitas Diponegoro).

Gordon, E. A. and Henry, E. (2005). Related Party Transactions and Earnings Management. https://papers.ssrn.com/sol3/papers.cfm?abstract_id=612234.

Habib, A., Jiang, H., and Zhou, D. (2015). Related-Party Transactions and Audit Fees: Evidence from China. Journal of International Accounting Research 14, 5983. doi: 10.2308/jiar-51020.

Jensen, M. C. and Meckling, W. H. (1976). Theory of The Firm: Managerial Behavior, Agency Costs and Ownership Structure. Journal of Financial Economics 3, 305-360. doi: 10.1016/0304-405x(76)90026-x.

Jian, M. and Wong, T. J. (2004). Earnings Management and Tunneling Through Related Party Transactions: Evidence from Chinese Corporate Groups. In EFA 2003 Annual Conference Paper No. 549, ed. and others.

Kohibeck, M. and Brian W, M. (2014). Are Related Party Transaction Red Flags? SSRN Electronic Journal.

Kohlbeck, M. and Mayhew, B. W. (2010). Valuation of firms that disclose related party transactions. Journal of Accounting and Public Policy 29, 115-137. doi: 10.1016/j.jaccpubpol.2009.10.006.
Simunic, D. (1980). The Pricing of Audit Services: Theory and Evidence. Journal of Accounting Research 18, 161-161. doi: 10.2307/2490397.

Tuanakotta, T. M. (2015). Audit Kontemporer (Jakarta: Salemba Empat.).

Wong, R. M. K., Kim, J.-B., and Lo, A. W. Y. (2015). Are Related-Party Sales ValueAdding or Value-Destroying? Evidence from China. Journal of International Financial Management \& Accounting 26, 1-38. doi: 10.1111/jifm.12023.

Conflict of Interest Statement: The author declare that the research was conducted in the absence of any commercial or financial relationships that could be construed as a potential conflict of interest.

Copyright (C) 2020 Author. This is an open-access article distributed under the terms of the Creative Commons Attribution License (CC BY). The use, distribution or reproduction in other forums is permitted, provided the original author(s) and the copyright owner(s) are credited and that the original publication in this journal is cited, in accordance with accepted academic practice. No use, distribution or reproduction is permitted which does not comply with these terms. 


\section{LIST OF TABLES}

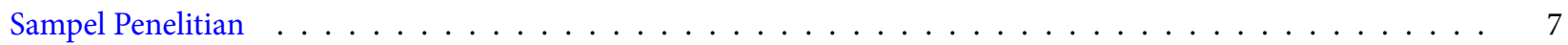

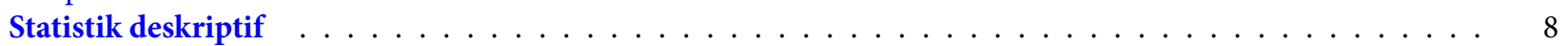

Uji Statistik . . . . . . . . . . . . . . . . . . . . . . . . . . . . 
TABLE 1 | Sampel Penelitian

\begin{tabular}{llll}
\hline No & Kriteria Sampel & 2017 & 2018 \\
1 & Perusahaan manufaktur yang terdaftar di BEI & 143 & 145 \\
2 & Laporan keuangan tidak dapat diakses & $(24)$ & $(21)$ \\
3 & Perusahaan yang tidakmengungkapkan biaya audit & $(64)$ & $(67)$ \\
4 & Perusahaan yang tidak melakukan transaksi dengan pihak berelasi & $(23)$ & $(22)$ \\
& Total & 32 & 35 \\
& Total Observasi & 67 & \\
\hline
\end{tabular}


TABLE 2 | Statistik deskriptif

\begin{tabular}{|c|c|c|c|c|c|}
\hline & & Minimum & Maximum & Mean & Std. Deviation \\
\hline AudFee & 67 & 18.60 & 23.32 & 20.8392 & 1.20800 \\
\hline PRT & 67 & .007 & .90 & .1977 & .23134 \\
\hline $\mathrm{ROA}$ & 67 & -.29 & .21 & .0316 & .07941 \\
\hline SIZE & 67 & 26.44 & 31.68 & 28.9471 & 1.36233 \\
\hline Valid N (listwise) & 67 & & & & \\
\hline \multicolumn{6}{|l|}{ Variabel Dummy } \\
\hline \multirow[t]{2}{*}{ Variabel } & \multirow{2}{*}{\multicolumn{2}{|c|}{ \%Score1 }} & \%Score0 & & total $\%$ \\
\hline & & & (29) $43,3 \%$ & & (67) $100 \%$ \\
\hline
\end{tabular}


TABLE 3 | Uji Statistik

\begin{tabular}{llll}
\hline Variabel & \multicolumn{2}{l}{$\begin{array}{l}\text { Regresi } \\
\text { Berganda }\end{array}$} & Linier \\
& \multicolumn{2}{c}{ t } & Sig \\
(Constantat) & 6,052 & 3,199 & 0,002 \\
RPT & 1,058 & 2,853 & 0,006 \\
ROA & 0,766 & 0,756 & 0,453 \\
BIG4 & 0,824 & 4,244 & 0,000 \\
SIZE & 0,487 & 7,270 & 0,000 \\
Adjustes R2 & 0,723 & & \\
F-value & 44,137 & & \\
Sig & 0,000 & & \\
\hline
\end{tabular}




\section{LIST OF FIGURES}

$1 \quad$ Kerangka Berfikir 


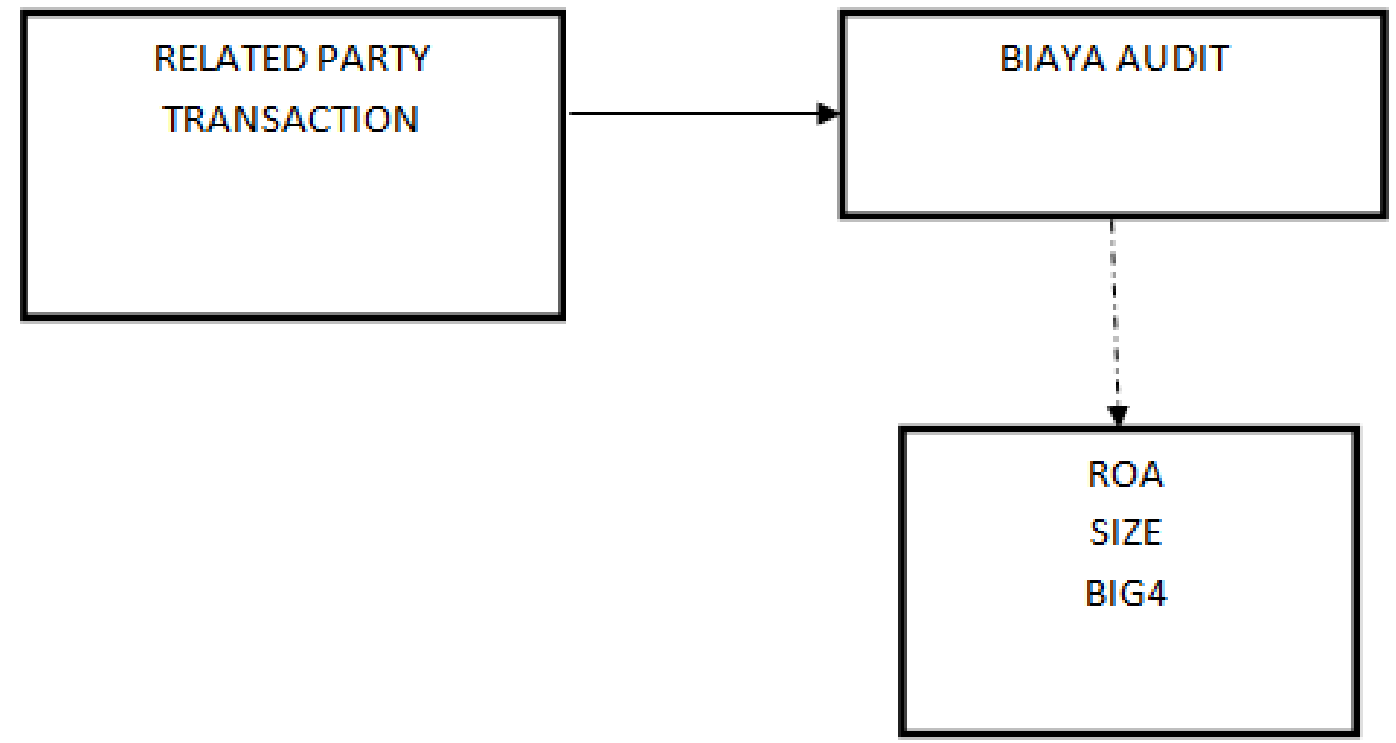

FIGURE 1 | Kerangka Berfikir 